\section{OPEN ACCESS}

Edited by: Isabelle Meyts, KU Leuven, Belgium

Reviewed by: Tri Giang Phan, Garvan Institute of Medical Research, Australia

Sylvain Latour,

Centre National de la Recherche Scientifique (CNRS), France

*Correspondence: Claire Booth c.booth@ucl.ac.uk; Pamela L. Schwartzberg pams@mail.nih.gov

Specialty section: This article was submitted to Primary Immunodeficiencies, a section of the journal Frontiers in Immunology

Received: 20 November 2017 Accepted: 19 March 2018

Published: 04 April 2018

Citation:

Panchal N, Booth C, Cannons JL and Schwartzberg PL (2018)

$X$-Linked Lymphoproliferative Disease

Type 1: A Clinical and Molecular

Perspective.

Front. Immunol. 9:666. doi: 10.3389/fimmu.2018.00666

\title{
X-Linked Lymphoproliferative Disease Type 1: A Clinical and Molecular Perspective
}

\author{
Neelam Panchal ${ }^{1}$, Claire Booth ${ }^{1,2 *}$, Jennifer L. Cannons ${ }^{3,4}$ and Pamela L. Schwartzberg ${ }^{3,4 *}$ \\ ${ }^{1}$ Molecular and Cellular Immunology Section, Great Ormond Street Institute of Child Health, University College London, \\ London, United Kingdom, ${ }^{2}$ Department of Pediatric Immunology, Great Ormond Street Hospital for Children NHS Foundation \\ Trust, London, United Kingdom, ${ }^{3}$ National Human Genome Research Institute, National Institutes of Health, Bethesda, MD, \\ United States, ${ }^{4}$ National Institute of Allergy and Infectious Diseases, National Institutes of Health, Bethesda, MD, United States
}

X-linked lymphoproliferative disease (XLP) was first described in the 1970s as a fatal lymphoproliferative syndrome associated with infection with Epstein-Barr virus (EBV). Features include hemophagocytic lymphohistiocytosis $(H\llcorner H)$, lymphomas, and dysgammaglobulinemias. Molecular cloning of the causative gene, SH2D1A, has provided insight into the nature of disease, as well as helped characterize multiple features of normal immune cell function. Although XLP type 1 (XLP1) provides an example of a primary immunodeficiency in which patients have problems clearing primarily one infectious agent, it is clear that XLP1 is also a disease of severe immune dysregulation, even independent of EBV infection. Here, we describe clinical features of XLP1, how molecular and biological studies of the gene product, SAP, and the associated signaling lymphocyte activation molecule family receptors have provided insight into disease pathogenesis including specific immune cell defects, and current therapeutic approaches including the potential use of gene therapy. Together, these studies have helped change the outcome of this once almost uniformly fatal disease.

\begin{abstract}
Keywords: X-linked lymphoproliferative disease 1, Epstein-Barr virus, SAP (signaling lymphocyte activation molecule-associated protein), signaling lymphocytic activation molecule, primary immunodeficiency disease, hemophagocytic lymphohistiocytosis, hematopoietic stem cell transfer, gene therapy
\end{abstract}

\section{INTRODUCTION}

Epstein-Barr virus (EBV) is a highly prevalent human gamma herpes virus that is spread via saliva and primarily infects the oropharyngeal epithelium and B cells (1). Infection in children is usually very mild, whereas in teenager and adults, it can result in a picture of infectious mononucleosis (IM) with fevers, flu-like symptoms, and even systemic lymphoproliferative disease. Studies suggest that EBV has infected approximately $90 \%$ of adults. After infection, EBV remains latent in B cells for the remainder of the life of the host, and although most people remain asymptomatic, it can cause B cell and T cell lymphomas, Hodgkin lymphoma, and Burkitt's lymphoma in certain groups, particularly in immunocompromised patients (2).

A major and critical issue with EBV arises in the case of such immunocompromised individuals, including those presenting with monogenic deficiencies, where EBV infection leads to a wide range of clinical complications and acquired disease phenotypes (3). In this review article, we will explore the disease pathologies arising in patients with a rare form of primary immunodeficiency (PID), 
X-linked lymphoproliferative disease type 1 (XLP1), which is perhaps the classic example of a PID associated with an inability to clear EBV (3-5).

\section{EBV IN XLP DISEASE}

\section{Characterization of Early Cases}

X-linked lymphoproliferative disease or Duncan's disease was described in the mid-1970s by Purtilo and colleagues in the Duncan kindred, where 6 out of 18 young males died of a lymphoproliferative disorder $(6,7)$. Three of these males had IM either immediately prior to or concurrent with the development of disease, which included fatal IM, hemophagocytic syndrome, and $\mathrm{B}$ cell malignancies, as well as humoral immune defects such as dysgammaglobulinemia. The observation of EBV-driven manifestations associated with a primary immune-deficiency catalyzed the recognition of XLP. Of note, two other contemporary reports also described families with males who succumbed to lymphoproliferative disorders and/or agammaglobulinemia associated with EBV infection, who may have had the same syndrome $(8,9)$.

Early investigations carried out by Purtilo and his team aimed to understand why EBV infection led to such aggressive and often fatal clinical phenotypes in these patients. In 1980, an XLP registry was established (7), which tracked presumed XLP patients with regard to disease onset and progression. The study revealed that the majority of patients had succumbed to IM due to extensive liver pathology and lymphoid infiltration of organs. However, those who did survive, as well as some EBV-negative male relatives, still progressed to develop dysgammaglobulinemia and/or B cell malignancies (10, 11). By 1995, over 270 boys were registered from over 80 kindreds (12); the overall mortality was reported as $75 \%$ with the majority of boys dying before 10 years of age, proving the severity of this condition.

The cloning of the gene, $S H 2 D 1 A$, responsible for this disease both revealed phenotypes in family members before they presented with the classic picture of EBV-induced pathology and allowed further molecular understanding of what is now called XLP type 1 (XLP1) (13-15). Clinical manifestations of XLP1 are now recognized to include a wider range of phenotypes associated with immune dysregulation even independent of EBV infection $(5,16)$. It should be noted that mutations in a second gene, BIRC4, encoding the X-linked inhibitor of apoptosis, XIAP, have been described in a subset of XLP patients who did not carry mutations in SH2D1A (now referred to as having XLP2) (17). However, XLP2 is more closely associated with EBV-driven hemophagocytic lymphohistiocytosis (HLH), as well as other clinical features not found consistently in XLP1 such as splenomegaly and colitis and will not be discussed further in this review $(17,18)$.

\section{Clinical Features}

The main clinical features of XLP1 remain HLH, dysgammaglobulinemia, and lymphoma but other described manifestations include aplastic anemia, vasculitis, chronic gastritis, and skin lesions $(12,19-24)$. HLH is the most common and lethal presentation, tending to occur early in childhood and associated with significant mortality, with a proportion of patients succumbing before hematopoietic stem cell transplant (HSCT) (16). HLH is a multisystem syndrome caused by hyperinflammation resulting in immune dysregulation, tissue damage, and often multiorgan failure. The main features are fever, cytopenias, and hepatosplenomegaly but involvement of other organs is often seen. Diagnostic criteria are available (25).

Up to $50 \%$ of patients demonstrate a range of humoral immune abnormalities, ranging from impaired vaccine responses to generalized hypo-gammaglobulinemia $(10,12,16)$. These may be incidental findings during diagnostic workup or lead to recurrent infections, particularly respiratory infections. Almost a third of patients develop lymphoma with the most common form being abdominal B cell non-Hodgkin lymphoma in both EBV + and EBV - patients; prognosis has dramatically improved over the decades due to improved chemotherapy protocols.

Analyses of mutations have revealed deletions, splice site, nonsense, and missense changes in SH2D1A, but so far, there has not been a clear correlation between mutations and the severity of phenotypes identified $(16,26)$. Patients can progress from one phenotype to another, and different clinical features are seen within members of the same family. However, in some cases, second-site reversions of missense and nonsense mutations have been found, which were associated with restored CD8 cell function in a small fraction of cells and less severe phenotypes (27).

It is important to highlight that up to $35 \%$ of patients have no evidence of previous EBV infection; many of these patients are diagnosed based on family history $(16,28,29)$. In EBV- patients, XLP1 is associated with higher rates of dysgammaglobulinemia (51.8 vs $37.2 \%$ for EBV+) and lymphoma [25 vs $19.6 \%$ for EBV+, see Table 2 from Ref. (16)]. However, EBV-negative boys with XLP1 can still develop HLH, although less frequently than those with EBV infection (21.4 vs $51 \%$ for EBV+) (16), and the trigger is unknown. Thus, XLP1 must be thought of as a disorder of immune dysregulation not only triggered by EBV. Nonetheless, there are no reports in the literature of a specific pathogen other than EBV being linked to HLH or other clinical features, arguing that XLP1 patients are specifically susceptible to EBV rather than other pathogens.

The overall mortality of the disease has reduced significantly since first reports from the registry, from 75 to $29 \%$ (16), largely due to improved chemotherapy and HSCT protocols, as well as improved monitoring and supportive care (which will be discussed later in this review). However, patients diagnosed at birth through family history still risk significant mortality despite close monitoring, highlighting the severity of this PID.

\section{MOLECULAR INSIGHT INTO PHENOTYPES OF XLP1}

Improved description of patient cohorts combined with the evolution of molecular techniques has widened our understanding of XLP1. However, equally important has been the investigation of the genetic cause of XLP1 and how lymphocyte development and function are affected by mutations of $\operatorname{SH} 2 \mathrm{D} 1 A(4,30)$. 


\section{Cloning of the Gene and Studies of SAP-Mediated Signaling}

In 1998, three groups identified a gene, now known as $S H 2 D 1 A$, that was mutated in patients with XLP. While two groups identified this gene by positional cloning $(13,31)$, a third group independently identified the same gene as encoding a small adaptor molecule that bound to the cytoplasmic tail of a T cell costimulatory protein, signaling lymphocyte activation molecule (SLAM) (14). Genetic mapping and sequencing revealed that this gene was mutated in samples from several XLP patients (14). The identification of SH2D1A has helped identify patients with the disease, but has also led to new insight into the signaling pathways regulated by SLAM family members and how they contribute to the pathophysiology of XLP1 $(4,5,32)$.

The evaluation of the predicted gene product revealed that SH2D1A encodes a small $(14 \mathrm{kDa} / 128 \mathrm{aa})$ protein that is now known as SAP, or SLAM-associated protein (14). Intriguingly, SAP consists almost entirely of a single Src Homology 2 (SH2) domain, a conserved protein interaction module that binds to phosphotyrosine-based motifs. SH2 domains are usually part of larger multi-domain proteins involved in signaling pathways, including adaptor molecules that contain multiple protein-protein and/or protein-lipid interaction domains and enzymes such as kinases and phosphatases that are regulated by intra- and intermolecular SH2-protein interactions (33). Further experiments demonstrated that the $\mathrm{SH} 2$ domain of SAP bound specific tyrosines on the intracellular tail of SLAM and related receptors $(34,35)$. However, these observations raised questions on how a single protein interaction domain could regulate signaling and how the disruption of SAP expression led to phenotypes associated with XLP1.

Although SAP was first identified by virtue of its association with SLAM, a costimulatory receptor that helps regulate interferon gamma cytokine production by T cells, SAP is now known to bind to a series of related receptors, the SLAM family, which include SLAM/CD150 (SLAMF1), LY9/CD229 (SLAMF3), 2B4/ CD244 (SLAMF4), CD84 (SLAMF5), NTB-A/Ly108/CD352 (SLAMF6), and CRACC/CD319 (SLAMF7) (36). These receptors are encoded in a highly polymorphic gene cluster on human and mouse chromosome 1, variants of which have been associated with predispositions to autoimmunity (37). With the exception of $2 \mathrm{~B} 4$, these receptors are self-ligands and are activated by homophilic interactions $(30,36)$. The SLAM family also has homology to the larger CD2 superfamily of immunoglobulin domain containing receptors, which include CD48/SLAMF2 (the ligand for 2B4/SLAMF4). SLAM receptors exhibit a broad expression on hematopoietic cells; however, several members are most highly expressed on B cells (38-41), a feature that likely contributes to some of the B cell-specific phenotypes of XLP1 (42). By contrast, although some $\mathrm{B}$ cell expression has also been reported $(35,43,44)$, SAP is most highly expressed in T and NK cells and is therefore most likely to affect SLAM family function in these cells $(14,45)$. Several of the SLAM family members, including 2B4/SLAMF4, NTB-A/SLAMF6, and CRACC/SLAMF7, have been implicated as cytotoxic receptors in NK and CD8 cells (30).

Extensive work on SAP-mediated signaling pathways provided evidence that SAP serves as a molecular switch allowing SLAM family members to act as either activating receptors in the presence of SAP or inhibitory receptors in the absence of SAP (Figure 1) $(30,35,36,46,47)$. Thus, when SAP is present, it can recruit the FYN tyrosine kinase, leading to further tyrosine phosphorylation of SLAM family members (48-50) and interactions with other signaling molecules, including RasGAP, Shc, Dok1, and Dok2 in the case of SLAM (51) and Vav1 and c-Cbl in the case of 2B4 and Ly108 (41, 45, 52). Notably, Fyn deficiency can phenocopy some features of SAP deficiency including defects in 2B4-mediated killing (50). SAP has also been shown to inhibit diacylglycerol kinase- $\alpha(\mathrm{DGK} \alpha)$, a molecule that negatively affects TCR signaling (53). However, when SAP is not expressed, the same tyrosines on SLAM family members bind a number of strong inhibitory molecules, including the tyrosine phosphatases SHP1 and SHP2, as well as the lipid phosphatase SHIP $(35,41,46$, $47,54)$. These inhibitory molecules essentially block aspects of $\mathrm{T}$ and NK cell activation, development and function when SLAM family members are engaged in the absence of SAP. Accordingly, the tyrosine-based motif that SAP recognizes has been coined an "ImmunoTyrosine Switch Motif" or ITSM (35).

Early data provided evidence that NK and CD8 cells from XLP patients exhibited defective killing of EBV-infected B cells $(55,56)$; this was linked to impaired killing via 2B4/SLAMF4 and NTB-A/SLAMF6 (57-60). Intriguingly, some data demonstrated that in the absence of SAP, 2B4/SLAMF4 prevented the killing of EBV-infected cells, providing further evidence that the SLAM family could act as inhibitory receptors (58). Combined with the biochemical evidence for the inhibitory function of SLAM family receptors, these results provided insight into why XLP1 patients have specific susceptibility to EBV infection. More recently, T cells from XLP1 patients have been found to exhibit defects in reactivation-induced cell death (RICD), resulting from inhibitory signaling from NTB-A/SLAMF6. This defect has been proposed to contribute to lymphoproliferation seen in XLP1 (61).

\section{Insight From Mouse Models}

The generation and study of SAP-deficient mice (62-64) has provided insight into additional phenotypes associated with SAP deficiency, some of which have subsequently been confirmed in XLP1 patients. One of these is a lack of invariant NKT cells, a rare innate type of $\mathrm{T}$ lymphocyte that rapidly responds to infection and may be involved in tumor surveillance-this defect was recognized due to the connection with Fyn, which also affects NKT cell development in mice (65-67). Whether and how the absence of NKT cells contributes to manifestations of XLP1 remains less well understood, but it is now appreciated that XLP1 patients exhibit an absolute lack of iNKT cells, independent of EBV infection status. The critical role of SAP in iNKT development is supported by studies of $S H 2 D 1 A$ carriers demonstrating random $\mathrm{X}$-inactivation in $\mathrm{T}$ and $\mathrm{B}$ cells but non-random $\mathrm{X}$-inactivation in iNKT cells, suggesting an absolute requirement of SAP for the development of this population (66).

Another major phenotype is the lack of long-term humoral (antibody) responses and memory B cells, which have been observed both in response to infection and to immunization in SAP-deficient mice $(62,64,68-70)$. These phenotypes were T cell intrinsic and associated with impaired formation of germinal centers (GCs) $(68,70)$, the site where B cells undergo immunoglobulin 


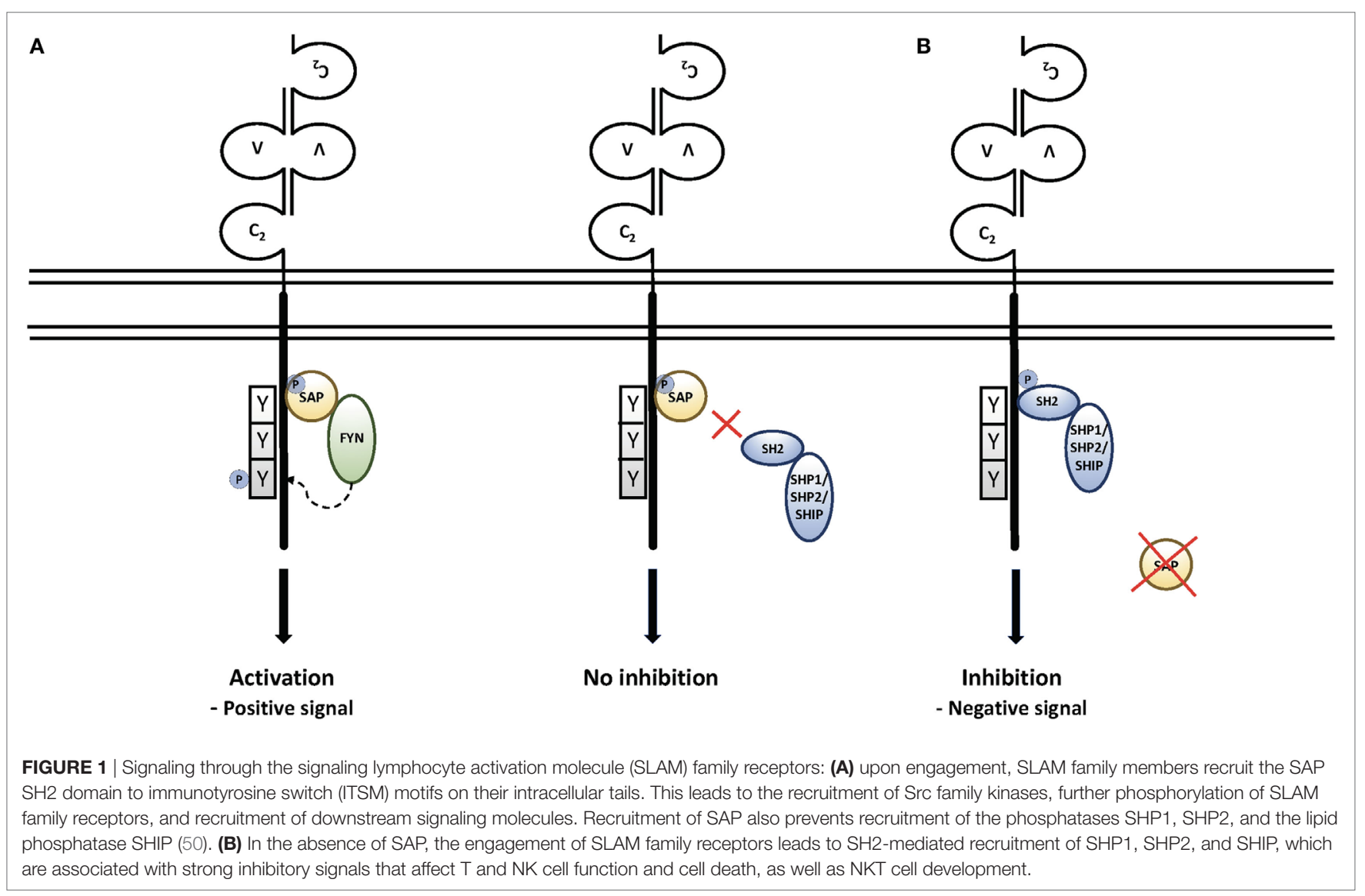

gene class-switching and hypermutation in response to antigen in the context of contact-dependent signals from specific CD4 $\mathrm{T}$ helper lymphocytes, now known as follicular $\mathrm{T}$ helper ( $\mathrm{Tfh}$ ) cells (71). The GC is also the site where most memory B cells and long-lived plasma cells are derived. Subsequent evaluation of XLP1 patients revealed that they also lacked $\operatorname{IgG}^{+}$memory (CD $27^{+}$) B cells, and an autopsy confirmed a lack of GCs in lymph nodes from an XLP1 patient (72). Interestingly, in addition to the well-documented dysgammaglobulinemia in XLP1 patients, evidence of impaired responses to protein immunization had been reported (73). However, the characterization of SAPdeficient mice has provided a clearer picture of the nature of these humoral defects (74).

Further insight into these phenotypes came from intravital microscopy in mice, which revealed that SAP-deficient T cells exhibited impaired adhesion to B cells, a defect that was confirmed using in vitro flow-based cell conjugation assays (75). This defect was relatively specific, as that adhesion to antigen-presenting dendritic cells was less affected. The B cell specificity correlated with very high levels of the expression of multiple SLAM family members including SLAMF6 (Ly108/NTB-A), SLAMF5 (CD84), and CD48 (the ligand for 2B4) on activated B cells $(38,40,42)$. In the absence of SAP, some of these ligands trigger an inhibitory response in SAP-deficient T cells, preventing full activation by and adhesion to B cells, likely by affecting TCR-induced insideout signaling to integrins $(76,77)$.
Consistent with these observations, SAP-deficient $\mathrm{T}$ cells are initially activated normally by antigen-presenting dendritic cells in response to immunization and infection, but fail to form mature Tfh cells, a process now recognized to require B cell interactions $(75,78,79)$. Indeed, insight into the critical role of Tfh cells in humoral immunity has been greatly advanced by studies of SAP-deficient mice. Such findings further suggested that defective adhesion to B cells was likely to contribute to the inability of SAP-deficient $\mathrm{T}$ cells to provide contact-dependent help for GC generation and long-term humoral immunity and thus the dysgammaglobulinemias seen in XLP1 $(42,75)$.

Moreover, the observation of defective interactions with B cells has provided mechanistic insight into other phenotypes of XLP1, many of which share a common feature of B cell involvement (Figure 2). SAP-deficient CD8 cells exhibit defective adhesion to and killing of activated B cell targets (39-41, 80), especially EBV-transformed cells, which express high levels of certain SLAM family members and CD48. Thus, the sensitivity to EBV may occur because EBV primarily infects B cells. Impaired immunosurveillance of B cell malignancies may contribute to the increased incidence of lymphomas, even in the absence of EBV infection $(16,42)$. Since defective CD8 and NK cell cytolysis have been linked to HLH, defects in killing EBV-infected B cells may trigger this phenotype as well (81), although the exact mechanism by which HLH develops in this population is yet to be elucidated. Moreover, since other hematopoietic cells also express SLAM 


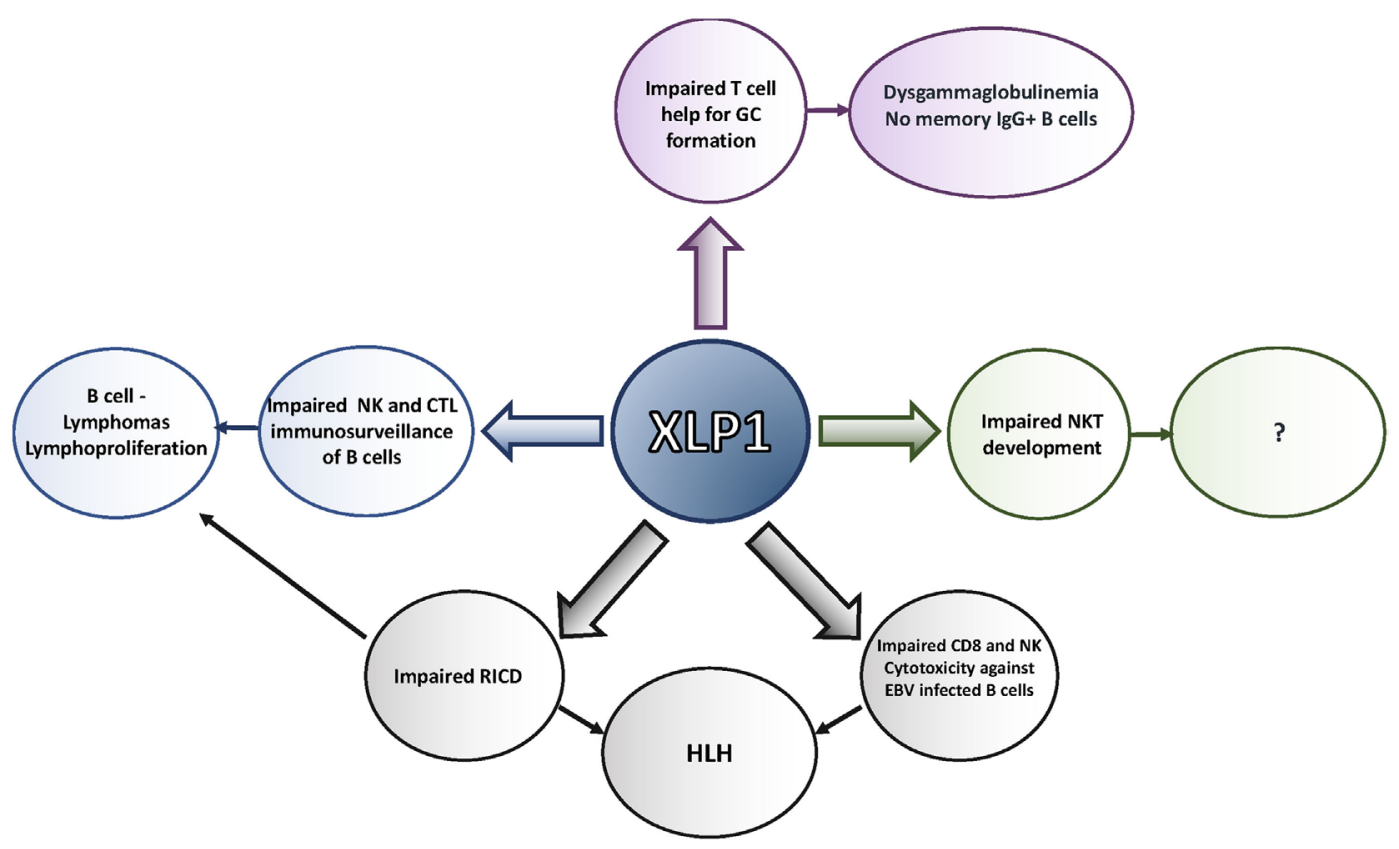

FIGURE 2 | Defects seen in X-linked lymphoproliferative disease (XLP)1. XLP1 is associated with multiple T and NK cellular defects, many of which may result from impaired interactions with B cells and other cells that express high levels of signaling lymphocyte activation molecule (SLAM) family members. These defects contribute to the phenotypes observed in the disease, including the inability to clear Epstein-Barr virus (EBV), lymphoproliferation and lymphoma, hemophagocytic lymphohistiocytosis (HLH), and antibody defects.

family members, defects may be extended to cytolysis of other hematopoietic targets; defects in NK cell cytolysis of multiple hematopoietic cell tumor lines that express SLAM family members have been observed (82). Nonetheless, it is also of note that NK cells deficient in SAP can kill non-hematopoietic cell targets better, perhaps accounting for the lack of increases in other types of cancer in XLP1 (83). Finally, the absence of NKT cells may result from impaired interactions between lymphocytes, as that NKT cells are not selected on the thymic stroma, but rather on double-positive thymocytes that express high levels of SLAM family members (84).

It is of note that the effects of SLAM family receptor mutations for the most part do not phenocopy those of SAP deficiency (85). Moreover, although polymorphisms of SLAM family members are associated with autoimmunity in lupus-prone mouse strains and humans (37), and with alterations in NKT cell numbers in NOD (non-obese diabetic) mice (86), to date, there have been no reports of immunodeficiency or EBV susceptibility associated with mutations of other SLAM family members in humans (36). Instead, many of the phenotypes of SAP deficiency appear to be related to inhibitory signals generated by SLAM family members in the absence of SAP $(39,76,85)$, which are most strongly triggered by $\mathrm{B}$ cell interactions, either as targets (for cytolysis) or as antigen presentation (GC formation). Notably, unlike positive signaling, these inhibitory signals would not be expected to rely on the ability of SAP to recruit Fyn. Indeed, several phenotypes associated with SAP deficiency can be rescued by the expression of a mutant of SAP that cannot recruit Fyn but can still block the recruitment of inhibitory molecules. These include humoral defects, NK cell killing, and NK cell education $(54,70,78,83)$, although some phenotypes such as 2B4-mediated killing and NKT cell development may result from defects in both positive and negative signals since Fyn deficiency also impairs these processes $(50,87)$. Importantly, unlike positive signaling, these negative signals require the presence of SLAM family members to recruit phosphatases and manifest their inhibitory function (Figure 1). Thus, inhibiting interactions of the SLAM family members 2B4/SLAMF4 and NTB-A/SLAMF6 with their ligands actually improves cytolysis of B cells by SAP-deficient CD8 cells and NK cells $(39,41,58)$. These observations suggest the intriguing possibility that blocking antibodies to SLAM family receptors might ameliorate some of the clinical manifestations of this disorder, raising the possibility of tailored SLAM family-based pharmacological approaches to XLP1 (see below). Support for this hypothesis can be found in murine genetic studies where mutations disrupting the expression of Ly108/SLAMF6 improved both the GC defect and NKT development in SAP-deficient mice (76).

\section{CURRENT TREATMENT AND MANAGEMENT OPTIONS FOR XLP1}

Given the severe morbidity and high rates of mortality in XLP1, it is strongly recommended that genetic screening and counseling be carried out in families with a history of XLP1 (5). Diagnosis is confirmed using flow cytometric analyses of SAP expression (88) followed by Sanger sequencing of the SH2D1A gene. Immunological status is assessed with focus on immunoglobulin levels and response to vaccines. 
Currently, the only definitive treatment available for XLP1 patients is allogeneic HSCT (16). However, depending on clinical features, less aggressive treatments may be adopted, particularly if a suitable donor for transplant is not available. As many patients do not present with all symptoms simultaneously or at varying severity, there are a number of treatment options that target specific clinical phenotypes.

\section{Treatment Approaches}

Treatment of XLP1 is tailored to particular clinical symptoms and supportive care. However, close monitoring (e.g., of EBV viral loads) is important in this patient cohort to allow the prevention of recurrent infections, organ damage such as bronchiectasis, and permit early treatment of EBV infection and more serious complications. If there is evidence of EBV-driven disease, including $\mathrm{HLH}$, treatment with a monoclonal anti-CD20 antibody (rituximab) can be used to deplete the $\mathrm{B}$ cell population harboring the virus (89). This approach is effective at reducing and often clearing the viremia but risks the effects of B cell depletion, including exacerbating long-term hypo-gammaglobulinemia. Antiviral agents are poorly effective against EBV but acyclovir has been used in some circumstances. Infection of $\mathrm{T}$ cells with EBV is also seen in XLP1 patients (unpublished data) and the use of rituximab in this situation may not be helpful.

Hemophagocytic lymphohistiocytosis is treated according to standardized protocols (HLH 94 and 2004) based on the use of dexamethasone, etoposide, and cyclosporin with the addition of intrathecal methotrexate and steroids if there is neurological involvement $(90,91)$. This is a highly suppressive regime and can be associated with significant toxicity. The protocol follows different stages, starting with an intense period of treatment initially, with reducing doses of steroids and frequency of etoposide over time if a response is seen. Re-intensification of therapy is occasionally required. This protocol aims to achieve remission of HLH, usually prior to moving swiftly to HSCT, but the mortality associated with this presentation is still over 60\% (16). Other immunosuppressive agents have been used to control HLH, either in combination with steroids or as rescue therapy, including ATG (anti-thymocyte globulin) in combination with etoposide in the HIT (hybrid ImmunoTherapy)-HLH trial (NCT01104025), or Alemtuzumab (Campath/anti CD52 antibody). In addition, newer biologics are now available, and some are being tested in HLH including Toculizumab (anti-IL6R antibody). An antiinterferon gamma monoclonal antibody (Novimmune NI-0501) is now in trial in the USA and Europe with results eagerly awaited. The JAK1/2 inhibitor Ruxolitinib has shown promise in preclinical murine studies and is now also moving toward the clinic (92).

These more targeted therapies could offer an improved toxicity profile, which may be extremely beneficial to help transition patients rapidly to HSCT with as little organ damage and infectious complications as possible and thereby afford better outcomes post transplant. Lymphoma is also treated according to standardized protocols, and again mortality associated with this presentation has reduced over the years.

Patients with dysgammaglobulinemia or recurrent infections may benefit from immunoglobulin replacement therapy which can be delivered via intravenous route every few weeks, or subcutaneously every week, which is usually performed at home. Other manifestations of dysregulation such as aplastic anemia or vasculitis may respond to steroid therapy or other immunosuppressive agents.

\section{Stem Cell Transplantation}

Bone marrow (BM) or HSC transplantation (which includes the transfer of $\mathrm{BM}$, mobilized $\mathrm{CD} 34^{+}$cells from peripheral blood or umbilical cord-derived CD $34^{+}$cells) is currently the only definitive treatment for XLP1; survival for untransplanted patients is below $20 \%$ (16). However, success is dependent on the availability of an appropriate donor who is human leukocyte antigen matched (16). There are a number of factors to consider prior to HSCT, including the disease status, previous treatments, and the type of pre-conditioning regimen. An EBV-positive donor is preferred in patients with EBV-driven disease.

Several studies have evaluated the clinical outcomes of patients undergoing HSCT using either myeloablative-conditioning regimens or reduced-intensity-conditioning (RIC) regimens $(16,93$, 94). These studies revealed similar overall patient survival rates post transplantation between RIC and myeloablative protocols, with both averaging $~ 80 \%(16,94)$. However, success rates drop depending on the presence of active HLH at the time of transplant (falling to 50\%) and in the context of a mismatched donor (16). From this large cohort, all patients who died post HSCT had evidence of HLH.

Thus, although the survival in XLP1 has improved significantly over time, it remains a potentially fatal condition. The decision to undertake an HSCT in an asymptomatic patient requires intensive discussion with the family to understand both risks and benefits, especially when a mismatched donor is the available choice. However, many families are faced with severe complications at presentation, such as HLH or lymphoma, which necessitate a rapid move to HSCT.

\section{Potential Future Therapies SLAM Family Inhibitors}

In the absence of SAP, the recruitment of phosphatases and other inhibitory signaling molecules convert SLAM family members into inhibitory receptors (4). This is particularly relevant for SLAMF4/2B4/CD244 and SLAMF6/NTB-A, which strongly inhibit CD8 and NK cell killing of B cell targets in the absence of SAP. Preventing SLAMF4/2B4 and/or SLAMF6/NTB-A engagement, either through genetic knockouts of these receptors in mice or through the use of blocking antibodies with human cells, can rescue phenotypes associated with SAP deficiency, including the defective killing of B cell targets, the absence of GC formation, defective NKT cell development, NK cell education, and impaired RICD (39, $41,61,76,83)$. Limiting the homophilic interactions of SLAM family receptors (or in the case of SLAMF4/2B4, interactions with its ligand, CD48) in XLP1 patients may therefore prevent lymphoproliferation and other phenotypes of XLP1. In vitro experiments have provided evidence that blocking antibodies against CD48 and NTB-A rescue killing of EBV-infected targets, supporting the concept of humanized blocking antibodies as a potentially useful therapy (39). Alternatively, peptide(s) or small molecules with a 
high affinity for the different SLAM receptors might block SLAM family interactions and the initiation of a negative signal.

Other potential therapeutic approaches include the use of small molecule inhibitors of signaling pathways affected by SAP and SLAM family members. The inhibition of SHP1/SHP2 rescued cytolysis of B cell targets in vitro using murine cells (41). Other data suggest that the inhibition of DGK $\alpha$, another negative regulator of $\mathrm{T}$ cell activation that is affected by SAP, can rescue certain phenotypes associated with SAP deficiency, including RICD and hyperproliferative responses to lymphochoriomeningitis virus in mice $(53,95)$. However, none of these approaches are curative, and toxicity may be a major issue, particularly for long-term treatment.

\section{Gene Therapy}

Over the last few years, there have been great strides developing effective and safe hematopoietic stem cell gene therapy as a viable alternative to BM transplantation for a number of PIDs. Gene therapy also offers the advantages of reduced toxicity from conditioning as, in general, less chemotherapy is required and the use of autologous cells removes the risk of graft versus host disease which causes significant morbidity and mortality post HSCT $(96,97)$. Although several first-generation gene therapy trials were marred by the integration of gammaretroviral vectors near proto-oncogenes leading to leukemia and myelodysplasia, newer self-inactivating (16) retroviruses and lentiviruses have been developed that use internal mammalian promoters to drive transgene expression. Numerous clinical trials are underway using these later generation vectors, and no insertional events have been reported to date.

A proof of concept for gene therapy for XLP1 was established using such a second-generation lentiviral vector containing the human elongation factor 1 alpha promoter to drive codonoptimized SAP gene expression (98). This study utilized a SAPdeficient murine model into which gene-corrected hematopoietic progenitor cells were infused following lethal irradiation. The transfer of gene-corrected cells led to the restoration of NK and CD8 T cell cytotoxicity, NKT development, as well as GC formation and function upon immunological challenge. However, although no adverse effects of SAP expression at the stem cell level were seen in these studies, SAP is a tightly regulated signaling protein that is predominately expressed in T cells $(14,45)$, and the use of a ubiquitous human promoter that can drive expression in all hematopoietic cells may not be optimal.

An alternative approach to more directly address the $\mathrm{T}$ celldependent clinical manifestations of XLP1 is to develop a therapeutic strategy using gene-corrected autologous patient T cells. Murine studies utilizing gene-modified T cell transfers into $S h 2 d 1 a^{-/ y}$ mice demonstrated the correction of Tfh cell function, the restoration of GCs, and the improvement in baseline immunoglobulin levels (Panchal et al., in press). In addition, the correction of $\mathrm{CD}^{+} \mathrm{T}$ cell function was shown using an in vivo tumor model. These data provide a strong case that adoptive $\mathrm{T}$ gene therapy may be a useful therapeutic option.

\section{Gene Editing}

Along with developments in gene therapy, the latter part of this decade has seen great advancements in the use of gene-editing platforms for therapeutic benefits (96, 99-101). Zinc finger nucleases have been established to be effective in eliminating CCR5 expression on $\mathrm{T}$ cells from HIV-infected individuals in order to prevent viral spread $(102,103)$. Transcription activator-like effector nucleases and CRISPR/Cas9 nuclease systems have been used for TCR knockdowns as part of CAR-T cell therapy, to produce an "off the shelf" donor $\mathrm{T}$ cell product for the treatment of $\mathrm{CD} 19^{+} \mathrm{B}$ cell leukemias $(104,105)$. Gene-editing platforms hold great promise for the effective correction of endogenous genes using corrected DNA copies as donor templates, utilizing the cell's own DNA repair machinery. This approach may be particularly beneficial for monogenic diseases such as XLP1 that can present with point mutations in the gene. Gene editing also offers a resolution to the issue of gene regulation and the risk of overexpression in anomalous hematopoietic compartments and could significantly improve the safety profile of genetically engineered cellular therapy $(100,106)$. However, this type of therapy needs to be custom-designed to repair the genetic defect of each patient and may not be useful for patients with gene deletions. Potential off-target effects also need to be carefully evaluated. Nonetheless, such approaches hold high potential for the treatment of PIDs.

\section{SUMMARY}

Over the last 30 years, the outcome for patients with XLP1 has significantly improved, mainly due to improvements in the treatment of clinical manifestations such as HLH and lymphoma. Survival post HSCT has also improved, but mortality associated with active disease at the time of transplant and mismatched donor settings remains significant. As our understanding of the molecular and cellular pathology in XLP1 continues to expand, novel treatments, including gene therapy, will continue to be developed, hopefully leading to even greater improved outcomes for patients with this devastating disease.

\section{AUTHOR CONTRIBUTIONS}

NP, CB, JC, and PS all contributed to the writing and editing of this manuscript. NP and PS generated the figures.

\section{ACKNOWLEDGMENTS}

The authors would like to thank the patients, clinicians, and scientists who have contributed to our knowledge of XLP1 and apologize to those we have not fully cited due to space. The authors also thank members of the Schwartzberg and Booth laboratories for their assistance in this work.

\section{FUNDING}

This work was supported in part by intramural funding from the National Human Genome Research Institute and the National Institutes of Allergy and Infectious Diseases, National Institutes of Health (PS and JC), and the Great Ormond Street Hospital Children's Charity (CB and NP). 


\section{REFERENCES}

1. Cohen JI. Epstein-Barr virus infection. N Engl J Med (2000) 343(7):481-92. doi:10.1056/NEJM200008173430707

2. Thorley-Lawson DA, Gross A. Persistence of the Epstein-Barr virus and the origins of associated lymphomas. N Engl J Med (2004) 350(13):1328-37. doi:10.1056/NEJMra032015

3. Worth AJ, Houldcroft CJ, Booth C. Severe Epstein-Barr virus infection in primary immunodeficiency and the normal host. Br J Haematol (2016) 175(4):559-76. doi:10.1111/bjh.14339

4. Tangye SG. XLP: clinical features and molecular etiology due to mutations in SH2D1A encoding SAP. J Clin Immunol (2014) 34(7):772-9. doi:10.1007/ s10875-014-0083-7

5. Zhang K, Wakefield E, Marsh R. Lymphoproliferative disease, X-linked. In: Adam MP, Ardinger HH, Pagon RA, Wallace SE, Bean LJH, Stephens $\mathrm{K}$, et al., editors. GeneReviews(R). Seattle: University of Washington, Seattle University of Washington (1993).

6. Purtilo DT, Cassel CK, Yang JP, Harper R. X-linked recessive progressive combined variable immunodeficiency (Duncan's disease). Lancet (1975) 1(7913):935-40. doi:10.1016/S0140-6736(75)92004-8

7. Purtilo DT. Immunopathology of X-linked lymphoproliferative syndrome. Immunol Today (1983) 4(10):291-7. doi:10.1016/0167-5699(83)90139-1

8. Bar RS, DeLor CJ, Clausen KP, Hurtubise P, Henle W, Hewetson JF. Fatal infectious mononucleosis in a family. N Engl J Med (1974) 290(7):363-7. doi:10.1056/NEJM197402142900704

9. Provisor AJ, Iacuone JJ, Chilcote RR, Neiburger RG, Crussi FG. Acquired agammaglobulinemia after a life-threatening illness with clinical and laboratory features of infectious mononucleosis in three related male children. $N$ Engl J Med (1975) 293(2):62-5. doi:10.1056/NEJM197507102930202

10. Grierson H, Purtilo DT. Epstein-Barr virus infections in males with the X-linked lymphoproliferative syndrome. Ann Intern Med (1987) 106(4):53845. doi:10.7326/0003-4819-106-4-538

11. Harrington DS, Weisenburger DD, Purtilo DT. Malignant lymphoma in the X-linked lymphoproliferative syndrome. Cancer (1987) 59(8):1419-29. doi:10.1002/1097-0142(19870415)59:8<1419::AID-CNCR2820590807> 3.0.CO;2-P

12. Seemayer TA, Gross TG, Egeler RM, Pirruccello SJ, Davis JR, Kelly CM, et al. $\mathrm{X}$-linked lymphoproliferative disease: twenty-five years after the discovery. Pediatr Res (1995) 38(4):471-8. doi:10.1203/00006450-199510000-00001

13. Coffey AJ, Brooksbank RA, Brandau O, Oohashi T, Howell GR, Bye JM, et al. Host response to EBV infection in $\mathrm{X}$-linked lymphoproliferative disease results from mutations in an SH2-domain encoding gene. Nat Genet (1998) 20(2):129-35. doi:10.1038/2424

14. Sayos J, Wu C, Morra M, Wang N, Zhang X, Allen D, et al. The X-linked lymphoproliferative-disease gene product SAP regulates signals induced through the co-receptor SLAM. Nature (1998) 395(6701):462-9. doi:10.1038/26683

15. Nichols KE, Ma CS, Cannons JL, Schwartzberg PL, Tangye SG. Molecular and cellular pathogenesis of X-linked lymphoproliferative disease. Immunol Rev (2005) 203:180-99. doi:10.1111/j.0105-2896.2005.00230.x

16. Booth C, Gilmour KC, Veys P, Gennery AR, Slatter MA, Chapel H, et al. $\mathrm{X}$-linked lymphoproliferative disease due to SAP/SH2D1A deficiency: a multicenter study on the manifestations, management and outcome of the disease. Blood (2011) 117(1):53-62. doi:10.1182/blood-2010-06-284935

17. Rigaud S, Fondanèche MC, Lambert N, Pasquier B, Mateo V, Soulas P, et al. XIAP deficiency in humans causes an X-linked lymphoproliferative syndrome. Nature (2006) 444(7115):110-4. doi:10.1038/nature05257

18. Pachlopnik Schmid J, Canioni D, Moshous D, Touzot F, Mahlaoui N, Hauck F, et al. Clinical similarities and differences of patients with X-linked lymphoproliferative syndrome type 1 (XLP-1/SAP deficiency) versus type 2 (XLP-2/XIAP deficiency). Blood (2011) 117(5):1522-9. doi:10.1182/ blood-2010-07-298372

19. Rougemont AL, Fournet JC, Martin SR, de Saint-Basile G, Latour S, Primeau MN, et al. Chronic active gastritis in X-linked lymphoproliferative disease. Am J Surg Pathol (2008) 32(2):323-8. doi:10.1097/ PAS.0b013e318141fcal

20. Talaat KR, Rothman JA, Cohen JI, Santi M, Choi JK, Guzman M, et al. Lymphocytic vasculitis involving the central nervous system occurs in patients with X-linked lymphoproliferative disease in the absence of Epstein-Barr virus infection. Pediatr Blood Cancer (2009) 53(6):1120-3. doi:10.1002/pbc.22185
21. Loeffel S, Chang CH, Heyn R, Harada S, Lipscomb H, Sinangil F, et al Necrotizing lymphoid vasculitis in X-linked lymphoproliferative syndrome. Arch Pathol Lab Med (1985) 109(6):546-50.

22. Kanegane H, Ito Y, Ohshima K, Shichijo T, Tomimasu K, Nomura K, et al. X-linked lymphoproliferative syndrome presenting with systemic lymphocytic vasculitis. Am J Hematol (2005) 78(2):130-3. doi:10.1002/ ajh.20261

23. Dutz JP, Benoit L, Wang X, Demetrick DJ, Junker A, de Sa D, et al. Lymphocytic vasculitis in X-linked lymphoproliferative disease. Blood (2001) 97(1):95-100. doi:10.1182/blood.V97.1.95

24. Mejstríková E, Janda A, Hrusák O, Bucková H, Vlcková M, Hancárová $\mathrm{M}$, et al. Skin lesions in a boy with X-linked lymphoproliferative disorder: comparison of 5 SH2D1A deletion cases. Pediatrics (2012) 129(2):e523-8. doi:10.1542/peds.2011-0870

25. Freeman HR, Ramanan AV. Review of haemophagocytic lymphohistiocytosis. Arch Dis Child (2011) 96(7):688-93. doi:10.1136/adc.2009.176610

26. Sumegi J, Seemayer TA, Huang D, Davis JR, Morra M, Gross TG, et al. A spectrum of mutations in SH2D1A that causes X-linked lymphoproliferative disease and other Epstein-Barr virus-associated illnesses. Leuk Lymphoma (2002) 43(6):1189-201. doi:10.1080/10428190290026240

27. Palendira U, Low C, Bell AI, Ma CS, Abbott RJ, Phan TG, et al. Expansion of somatically reverted memory $\mathrm{CD}^{+} \mathrm{T}$ cells in patients with $\mathrm{X}$-linked lymphoproliferative disease caused by selective pressure from Epstein-Barr virus. J Exp Med (2012) 209(5):913-24. doi:10.1084/jem.20112391

28. Gilmour KC, Cranston T, Jones A, Davies EG, Goldblatt D, Thrasher A, et al. Diagnosis of X-linked lymphoproliferative disease by analysis of SLAM-associated protein expression. Eur J Immunol (2000) 30(6):1691-7. doi:10.1002/1521-4141(200006)30:6<1691::AID-IMMU1691>3.0.CO;2-K

29. Sumegi J, Huang D, Lanyi A, Davis JD, Seemayer TA, Maeda A, et al. Correlation of mutations of the SH2D1A gene and Epstein-Barr virus infection with clinical phenotype and outcome in X-linked lymphoproliferative disease. Blood (2000) 96(9):3118-25.

30. Cannons JL, Tangye SG, Schwartzberg PL. SLAM family receptors and SAP adaptors in immunity. Annu Rev Immunol (2011) 29:665-705. doi:10.1146/ annurev-immunol-030409-101302

31. Nichols KE, Harkin DP, Levitz S, Krainer M, Kolquist KA, Genovese C, et al. Inactivating mutations in an $\mathrm{SH} 2$ domain-encoding gene in X-linked lymphoproliferative syndrome. Proc Natl Acad Sci U S A (1998) 95(23):13765-70. doi:10.1073/pnas.95.23.13765

32. Cannons JL, Schwartzberg PL. SAP and lessons learned from a primary immunodeficiency. J Immunol (2017) 199(5):1531-3. doi:10.4049/ jimmunol.1701007

33. Pawson T, Nash P. Protein-protein interactions define specificity in signal transduction. Genes Dev (2000) 14(9):1027-47.

34. Poy F, Yaffe MB, Sayos J, Saxena K, Morra M, Sumegi J, et al. Crystal structures of the XLP protein SAP reveal a class of SH2 domains with extended, phosphotyrosine-independent sequence recognition. Mol Cell (1999) 4(4):555-61. doi:10.1016/S1097-2765(00)80206-3

35. Shlapatska LM, Mikhalap SV, Berdova AG, Zelensky OM, Yun TJ, Nichols $\mathrm{KE}$, et al. CD150 association with either the SH2-containing inositol phosphatase or the SH2-containing protein tyrosine phosphatase is regulated by the adaptor protein SH2D1A. J Immunol (2001) 166(9):5480-7. doi:10.4049/ jimmunol.166.9.5480

36. Wu N, Veillette A. SLAM family receptors in normal immunity and immune pathologies. Curr Opin Immunol (2016) 38:45-51. doi:10.1016/j. coi.2015.11.003

37. Chan AY, Westcott JM, Mooney JM, Wakeland EK, Schatzle JD. The role of SAP and the SLAM family in autoimmunity. Curr Opin Immunol (2006) 18(6):656-64. doi:10.1016/j.coi.2006.09.010

38. Cannons JL, Qi H, Lu KT, Dutta M, Gomez-Rodriguez J, Cheng J, et al. Optimal germinal center responses require a multistage $\mathrm{T}$ cell:B cell adhesion process involving integrins, SLAM-associated protein, and CD84. Immunity (2010) 32(2):253-65. doi:10.1016/j.immuni.2010.01.010

39. Hislop AD, Palendira U, Leese AM, Arkwright PD, Rohrlich PS, Tangye SG, et al. Impaired Epstein-Barr virus-specific $\mathrm{CD}^{+} \mathrm{T}$-cell function in $\mathrm{X}$-linked lymphoproliferative disease is restricted to SLAM family-positive B-cell targets. Blood (2010) 116(17):3249-57. doi:10.1182/blood-2009-09-238832

40. Palendira U, Low C, Chan A, Hislop AD, Ho E, Phan TG, et al. Molecular pathogenesis of EBV susceptibility in XLP as revealed by analysis of 
female carriers with heterozygous expression of SAP. PLoS Biol (2011) 9(11):e1001187. doi:10.1371/journal.pbio.1001187

41. Zhao F, Cannons JL, Dutta M, Griffiths GM, Schwartzberg PL. Positive and negative signaling through SLAM receptors regulate synapse organization and thresholds of cytolysis. Immunity (2012) 36(6):1003-16. doi:10.1016/j. immuni.2012.05.017

42. Schwartzberg PL, Mueller KL, Qi H, Cannons JL. SLAM receptors and SAP influence lymphocyte interactions, development and function. Nat Rev Immunol (2009) 9(1):39-46. doi:10.1038/nri2456

43. Morra M, Barrington RA, Abadia-Molina AC, Okamoto S, Julien A, Gullo C, et al. Defective B cell responses in the absence of SH2D1A. Proc Natl Acad Sci U S A (2005) 102(13):4819-23. doi:10.1073/pnas.0408681102

44. Menard L, Cantaert T, Chamberlain N, Tangye SG, Riminton S, Church JA, et al. Signaling lymphocytic activation molecule (SLAM)/SLAM-associated protein pathway regulates human B-cell tolerance. J Allergy Clin Immunol (2014) 133(4):1149-61. doi:10.1016/j.jaci.2013.10.051

45. Veillette A, Zhang S, Shi X, Dong Z, Davidson D, Zhong MC. SAP expression in T cells, not in B cells, is required for humoral immunity. Proc Natl Acad Sci U S A (2008) 105(4):1273-8. doi:10.1073/pnas.0710698105

46. Tangye SG, Lazetic S, Woollatt E, Sutherland GR, Lanier LL, Phillips JH. Cutting edge: human 2B4, an activating NK cell receptor, recruits the protein tyrosine phosphatase SHP-2 and the adaptor signaling protein SAP. J Immunol (1999) 162(12):6981-5.

47. Li C, Iosef C, Jia CY, Han VK, Li SS. Dual functional roles for the X-linked lymphoproliferative syndrome gene product SAP/SH2D1A in signaling through the signaling lymphocyte activation molecule (SLAM) family of immune receptors. JBiol Chem (2003) 278(6):3852-9. doi:10.1074/jbc. M206649200

48. Chan B, Lanyi A, Song HK, Griesbach J, Simarro-Grande M, Poy F, et al. SAP couples Fyn to SLAM immune receptors. Nat Cell Biol (2003) 5(2):155-60. doi:10.1038/ncb920

49. Latour S, Roncagalli R, Chen R, Bakinowski M, Shi X, Schwartzberg PL, et al. Binding of SAP SH2 domain to FynT SH3 domain reveals a novel mechanism of receptor signalling in immune regulation. Nat Cell Biol (2003) 5(2):149-54. doi:10.1038/ncb919

50. Bloch-Queyrat C, Fondanèche MC, Chen R, Yin L, Relouzat F, Veillette A, et al. Regulation of natural cytotoxicity by the adaptor SAP and the Src-related kinase Fyn. J Exp Med (2005) 202(1):181-92. doi:10.1084/jem.20050449

51. Latour S, Gish G, Helgason CD, Humphries RK, Pawson T, Veillette A. Regulation of SLAM-mediated signal transduction by SAP, the X-linked lymphoproliferative gene product. Nat Immunol (2001) 2(8):681-90. doi:10.1038/90615

52. Kim HS, Das A, Gross CC, Bryceson YT, Long EO. Synergistic signals for natural cytotoxicity are required to overcome inhibition by $\mathrm{c}$-Cbl ubiquitin ligase. Immunity (2010) 32(2):175-86. doi:10.1016/j.immuni.2010.02.004

53. Baldanzi G, Pighini A, Bettio V, Rainero E, Traini S, Chianale F, et al. SAPmediated inhibition of diacylglycerol kinase alpha regulates TCR-induced diacylglycerol signaling. J Immunol (2011) 187(11):5941-51. doi:10.4049/ jimmunol.1002476

54. Dong Z, Davidson D, Pérez-Quintero LA, Kurosaki T, Swat W, Veillette A. The adaptor SAP controls NK cell activation by regulating the enzymes Vav-1 and SHIP-1 and by enhancing conjugates with target cells. Immunity (2012) 36(6):974-85. doi:10.1016/j.immuni.2012.03.023

55. Sullivan JL, Byron KS, Brewster FE, Purtilo DT. Deficient natural killer cell activity in X-linked lymphoproliferative syndrome. Science (1980) 210(4469):543-5. doi:10.1126/science.6158759

56. Harada S, Bechtold T, Seeley JK, Purtilo DT. Cell-mediated immunity to Epstein-Barr virus (EBV) and natural killer (NK)-cell activity in the $\mathrm{X}$-linked lymphoproliferative syndrome. Int J Cancer (1982) 30(6):739-44. doi:10.1002/ijc.2910300610

57. Nakajima H, Cella M, Bouchon A, Grierson HL, Lewis J, Duckett CS, et al. Patients with X-linked lymphoproliferative disease have a defect in 2B4 receptor-mediated NK cell cytotoxicity. Eur J Immunol (2000) 30(11):3309-18. doi:10.1002/1521-4141(200011)30:11<3309::AID-IMMU3309>3.0.CO;2-3

58. Parolini S, Bottino C, Falco M, Augugliaro R, Giliani S, Franceschini R, et al. X-linked lymphoproliferative disease. 2B4 molecules displaying inhibitory rather than activating function are responsible for the inability of natural killer cells to kill Epstein-Barr virus-infected cells. J Exp Med (2000) 192(3):337-46. doi:10.1084/jem.192.3.337
59. Tangye SG, Phillips JH, Lanier LL, Nichols KE. Functional requirement for SAP in 2B4-mediated activation of human natural killer cells as revealed by the X-linked lymphoproliferative syndrome. J Immunol (2000) 165(6):29326. doi:10.4049/jimmunol.165.6.2932

60. Bottino C, Falco M, Parolini S, Marcenaro E, Augugliaro R, Sivori S, et al. NTB-A [correction of GNTB-A], a novel SH2D1A-associated surface molecule contributing to the inability of natural killer cells to kill Epstein-Barr virus-infected B cells in X-linked lymphoproliferative disease. J Exp Med (2001) 194(3):235-46. doi:10.1084/jem.194.3.235

61. Snow AL, Marsh RA, Krummey SM, Roehrs P, Young LR, Zhang K, et al. Restimulation-induced apoptosis of $\mathrm{T}$ cells is impaired in patients with $\mathrm{X}$-linked lymphoproliferative disease caused by SAP deficiency. J Clin Invest (2009) 119(10):2976-89. doi:10.1172/JCI39518

62. Czar MJ, Kersh EN, Mijares LA, Lanier G, Lewis J, Yap G, et al. Altered lymphocyte responses and cytokine production in mice deficient in the X-linked lymphoproliferative disease gene SH2D1A/DSHP/SAP. Proc Natl Acad Sci U $S$ A (2001) 98(13):7449-54. doi:10.1073/pnas.131193098

63. Wu C, Nguyen KB, Pien GC, Wang N, Gullo C, Howie D, et al. SAP controls $\mathrm{T}$ cell responses to virus and terminal differentiation of TH2 cells. Nat Immunol (2001) 2(5):410-4. doi:10.1038/87713

64. Yin L, Al-Alem U, Liang J, Tong WM, Li C, Badiali M, et al. Mice deficient in the X-linked lymphoproliferative disease gene sap exhibit increased susceptibility to murine gammaherpesvirus- 68 and hypo-gammaglobulinemia. J Med Virol (2003) 71(3):446-55. doi:10.1002/jmv.10504

65. Chung B, Aoukaty A, Dutz J, Terhorst C, Tan R. Signaling lymphocytic activation molecule-associated protein controls NKT cell functions. J Immunol (2005) 174(6):3153-7. doi:10.4049/jimmunol.174.6.3153

66. Nichols KE, Hom J, Gong SY, Ganguly A, Ma CS, Cannons JL, et al. Regulation of NKT cell development by SAP, the protein defective in XLP. Nat Med (2005) 11(3):340-5. doi:10.1038/nm1189

67. Pasquier B, Yin L, Fondanèche MC, Relouzat F, Bloch-Queyrat C, Lambert $\mathrm{N}$, et al. Defective NKT cell development in mice and humans lacking the adapter SAP, the X-linked lymphoproliferative syndrome gene product. J Exp Med (2005) 201(5):695-701. doi:10.1084/jem.20042432

68. Crotty S, Kersh EN, Cannons J, Schwartzberg PL, Ahmed R. SAP is required for generating long-term humoral immunity. Nature (2003) 421(6920):282-7. doi:10.1038/nature01318

69. Hron JD, Caplan L, Gerth AJ, Schwartzberg PL, Peng SL. SH2D1A regulates T-dependent humoral autoimmunity. J Exp Med (2004) 200(2):261-6. doi:10.1084/jem.20040526

70. Cannons JL, Yu LJ, Jankovic D, Crotty S, Horai R, Kirby M, et al. SAP regulates $\mathrm{T}$ cell-mediated help for humoral immunity by a mechanism distinct from cytokine regulation. J Exp Med (2006) 203(6):1551-65. doi:10.1084/ jem. 20052097

71. Victora GD, Nussenzweig MC. Germinal centers. Annu Rev Immunol (2012) 30:429-57. doi:10.1146/annurev-immunol-020711-075032

72. Ma CS, Pittaluga S, Avery DT, Hare NJ, Maric I, Klion AD, et al. Selective generation of functional somatically mutated $\operatorname{IgM}^{+} \mathrm{CD} 27^{+}$, but not $\mathrm{Ig}$ isotype-switched, memory B cells in X-linked lymphoproliferative disease. J Clin Invest (2006) 116(2):322-33. doi:10.1172/JCI25720

73. Ochs HD, Sullivan JL, Wedgwood RJ, Seeley JK, Sakamoto K, Purtilo DT. $\mathrm{X}$-linked lymphoproliferative syndrome: abnormal antibody responses to bacteriophage phi X 174. Birth Defects Orig Artic Ser (1983) 19(3):321-3.

74. Ma CS, Nichols KE, Tangye SG. Regulation of cellular and humoral immune responses by the SLAM and SAP families of molecules. Annu Rev Immunol (2007) 25:337-79. doi:10.1146/annurev.immunol.25.022106.141651

75. Qi H, Cannons JL, Klauschen F, Schwartzberg PL, Germain RN. SAPcontrolled T-B cell interactions underlie germinal centre formation. Nature (2008) 455(7214):764-9. doi:10.1038/nature07345

76. Kageyama R, Cannons JL, Zhao F, Yusuf I, Lao C, Locci M, et al. The receptor Ly108 functions as a SAP adaptor-dependent on-off switch for T cell help to B cells and NKT cell development. Immunity (2012) 36(6):986-1002. doi:10.1016/j.immuni.2012.05.016

77. Chu C, Wang Y, Zhang X, Ni X, Cao J, Xu W, et al. SAP-regulated T cellAPC adhesion and ligation-dependent and -independent Ly108-CD3zeta interactions. J Immunol (2014) 193(8):3860-71. doi:10.4049/jimmunol. 1401660

78. McCausland MM, Yusuf I, Tran H, Ono N, Yanagi Y, Crotty S. SAP regulation of follicular helper CD4 T cell development and humoral immunity 
is independent of SLAM and Fyn kinase. J Immunol (2007) 178(2):817-28. doi:10.4049/jimmunol.178.2.817

79. Crotty S. Follicular helper CD4 T cells (TFH). Annu Rev Immunol (2011) 29:621-63. doi:10.1146/annurev-immunol-031210-101400

80. Dupré L, Andolfi G, Tangye SG, Clementi R, Locatelli F, Aricò M, et al. SAP controls the cytolytic activity of $\mathrm{CD} 8^{+} \mathrm{T}$ cells against EBV-infected cells. Blood (2005) 105(11):4383-9. doi:10.1182/blood-2004-08-3269

81. Sepulveda FE, de Saint Basile G. Hemophagocytic syndrome: primary forms and predisposing conditions. Curr Opin Immunol (2017) 49:20-6. doi:10.1016/j.coi.2017.08.004

82. Dong Z, Cruz-Munoz ME, Zhong MC, Chen R, Latour S, Veillette A. Essential function for SAP family adaptors in the surveillance of hematopoietic cells by natural killer cells. Nat Immunol (2009) 10(9):973-80. doi:10.1038/ni.1763

83. Wu N, Zhong MC, Roncagalli R, Pérez-Quintero LA, Guo H, Zhang Z, et al. A hematopoietic cell-driven mechanism involving SLAMF6 receptor, SAP adaptors and SHP-1 phosphatase regulates NK cell education. Nat Immunol (2016) 17(4):387-96. doi:10.1038/ni.3369

84. Griewank K, Borowski C, Rietdijk S, Wang N, Julien A, Wei DG, et al. Homotypic interactions mediated by SLAMf1 and SLAMf6 receptors control NKT cell lineage development. Immunity (2007) 27(5):751-62. doi:10.1016/j. immuni.2007.08.020

85. Chen S, Cai C, Li Z, Liu G, Wang Y, Blonska M, et al. Dissection of SAPdependent and SAP-independent SLAM family signaling in NKT cell development and humoral immunity. J Exp Med (2017) 214(2):475-89. doi:10.1084/jem.20161312

86. Jordan MA, Fletcher JM, Pellicci D, Baxter AG. Slamf1, the NKT cell control gene Nkt1. J Immunol (2007) 178(3):1618-27. doi:10.4049/jimmunol. 178.3.1618

87. Gadue P, Morton N, Stein PL. The Src family tyrosine kinase Fyn regulates natural killer T cell development. J Exp Med (1999) 190(8):1189-96. doi:10.1084/jem.190.8.1189

88. Marsh RA, Bleesing JJ, Filipovich AH. Flow cytometric measurement of SLAM-associated protein and X-linked inhibitor of apoptosis. Methods Mol Biol (2013) 979:189-97. doi:10.1007/978-1-62703-290-2_15

89. Milone MC, Tsai DE, Hodinka RL, Silverman LB, Malbran A, Wasik MA, et al. Treatment of primary Epstein-Barr virus infection in patients with $\mathrm{X}$-linked lymphoproliferative disease using B-cell-directed therapy. Blood (2005) 105(3):994-6. doi:10.1182/blood-2004-07-2965

90. Bergsten E, Horne A, Aricó M, Astigarraga I, Egeler RM, Filipovich AH, et al. Confirmed efficacy of etoposide and dexamethasone in HLH treatment: long term results of the cooperative HLH-2004 study. Blood (2017) 130(25):2728-38. doi:10.1182/blood-2017-06-788349

91. Henter JI, Horne A, Aricó M, Egeler RM, Filipovich AH, Imashuku S, et al. HLH-2004: diagnostic and therapeutic guidelines for hemophagocytic lymphohistiocytosis. Pediatr Blood Cancer (2007) 48(2):124-31. doi:10.1002/pbc.21039

92. Das R, Guan P, Sprague L, Verbist K, Tedrick P, An QA, et al. Janus kinase inhibition lessens inflammation and ameliorates disease in murine models of hemophagocytic lymphohistiocytosis. Blood (2016) 127(13):1666-75. doi:10.1182/blood-2015-12-684399

93. Lankester AC, Visser LF, Hartwig NG, Bredius RG, Gaspar HB, van der Burg $\mathrm{M}$, et al. Allogeneic stem cell transplantation in X-linked lymphoproliferative disease: two cases in one family and review of the literature. Bone Marrow Transplant (2005) 36(2):99-105. doi:10.1038/sj.bmt.1705016
94. Marsh RA, Bleesing JJ, Chandrakasan S, Jordan MB, Davies SM, Filipovich AH. Reduced-intensity conditioning hematopoietic cell transplantation is an effective treatment for patients with SLAM-associated protein deficiency/X-linked lymphoproliferative disease type 1. Biol Blood Marrow Transplant (2014) 20(10):1641-5. doi:10.1016/j.bbmt.2014.06.003

95. Ruffo E, Malacarne V, Larsen SE, Das R, Patrussi L, Wülfing C, et al. Inhibition of diacylglycerol kinase alpha restores restimulation-induced cell death and reduces immunopathology in XLP-1. Sci Transl Med (2016) 8(321):321ra7. doi:10.1126/scitranslmed.aad 1565

96. Booth C, Gaspar HB, Thrasher AJ. Gene therapy for primary immunodeficiency. Curr Opin Pediatr (2011) 23(6):659-66. doi:10.1097/ MOP.0b013e32834cd67a

97. Ghosh S, Gaspar HB. Gene therapy approaches to immunodeficiency. Hematol Oncol Clin North Am (2017) 31(5):823-34. doi:10.1016/j.hoc.2017.05.003

98. Rivat C, Booth C, Alonso-Ferrero M, Blundell M, Sebire NJ, Thrasher AJ, et al. SAP gene transfer restores cellular and humoral immune function in a murine model of X-linked lymphoproliferative disease. Blood (2013) 121(7):1073-6. doi:10.1182/blood-2012-07-445858

99. Porteus MH. Towards a new era in medicine: therapeutic genome editing. Genome Biol (2015) 16:286. doi:10.1186/s13059-015-0859-y

100. Booth C, Gaspar HB, Thrasher AJ. Treating immunodeficiency through HSC gene therapy. Trends Mol Med (2016) 22(4):317-27. doi:10.1016/j. molmed.2016.02.002

101. Candotti F. Advances of gene therapy for primary immunodeficiencies. F1000Res (2016) 5:Rev-310. doi:10.12688/f1000research.7512.1

102. Holt N, Wang J, Kim K, Friedman G, Wang X, Taupin V, et al. Human hematopoietic stem/progenitor cells modified by zinc-finger nucleases targeted to CCR5 control HIV-1 in vivo. Nat Biotechnol (2010) 28(8):839-47. doi: $10.1038 /$ nbt. 1663

103. Cannon P, June C. Chemokine receptor 5 knockout strategies. Curr Opin HIV AIDS (2011) 6(1):74-9. doi:10.1097/COH.0b013e32834122d7

104. Georgiadis C, Qasim W. Emerging applications of gene edited T cells for the treatment of leukemia. Expert Rev Hematol (2017) 10(9):753-5. doi:10.1080 /17474086.2017.1350575

105. Qasim W, Zhan H, Samarasinghe S, Adams S, Amrolia P, Stafford S, et al. Molecular remission of infant B-ALL after infusion of universal TALEN gene-edited CAR T cells. Sci Transl Med (2017) 9(374):eaaj2013. doi:10.1126/ scitranslmed.aaj2013

106. Kohn DB, Kuo CY. New frontiers in the therapy of primary immunodeficiency: from gene addition to gene editing. J Allergy Clin Immunol (2017) 139(3):726-32. doi:10.1016/j.jaci.2017.01.007

Conflict of Interest Statement: The authors declare that the research was conducted in the absence of any commercial or financial relationships that could be construed as a potential conflict of interest.

Copyright (1) 2018 Panchal, Booth, Cannons and Schwartzberg. This is an openaccess article distributed under the terms of the Creative Commons Attribution License (CC BY). The use, distribution or reproduction in other forums is permitted, provided the original author(s) and the copyright owner are credited and that the original publication in this journal is cited, in accordance with accepted academic practice. No use, distribution or reproduction is permitted which does not comply with these terms. 